\title{
Water activity and activation diameters from hygroscopicity data - Part I: Theory and application to inorganic salts
}

\author{
S. M. Kreidenweis ${ }^{1}$, K. Koehler ${ }^{1}$, P. J. DeMott ${ }^{1}$, A. J. Prenni ${ }^{1}$, C. Carrico ${ }^{1}$, and B. Ervens ${ }^{2}$ \\ ${ }^{1}$ Department of Atmospheric Science, Colorado State University, Fort Collins, CO, 80523, USA \\ ${ }^{2}$ NOAA, Boulder, CO, 80503, USA
}

Received: 5 January 2005 - Published in Atmos. Chem. Phys. Discuss.: 25 January 2005

Revised: 2 May 2005 - Accepted: 7 May 2005 - Published: 8 June 2005

\begin{abstract}
A method is described that uses particle hygroscopicity measurements, made with a humidified tandem differential mobility analyzer (HTDMA), to determine solution water activity as a function of composition. The use of derived water activity data in computations determining the ability of aerosols to serve as cloud condensation nuclei $(\mathrm{CCN})$ is explored. Results for sodium chloride and ammonium sulfate are shown in Part I. The methodology yields solution water activities and critical dry diameters for ammonium sulfate and sodium chloride in good agreement with previously published data. The approach avoids the assumptions required for application of simplified and modified Köhler equations to predict CCN activity, most importantly, knowledge of the molecular weight and the degree of dissociation of the soluble species. Predictions of the dependence of water activity on the mass fraction of aerosol species are sensitive to the assumed dry density, but predicted critical dry diameters are not.
\end{abstract}

\section{Introduction}

The water activity of solutions comprising atmospheric particles is a key parameter describing particles' equilibrium interactions with water vapor. For example, water activity data are used to calculate the supersaturation required for particles to activate as cloud condensation nuclei (CCN), and also to compute equilibrium water contents below $100 \%$ relative humidity for visibility and direct radiative forcing calculations. The relative efficiency of various species in nucleating cloud droplets can be, and has been, investigated directly in the laboratory. However, such measurements, typically made using a thermogradient diffusion chamber, require very stable supersaturations for reliable results, which can be diffi-

Correspondence to: K. Koehler

(kkoehler@lamar.colostate.edu) cult to maintain. Further, data from the diffusion chambers do not provide any quantitative information on water uptake below the critical supersaturation. It is desirable to develop a methodology to provide data on aerosol-water vapor interactions through the full range of relevant atmospheric saturation ratios.

In this work, we investigate the use of water uptake data for particles below water saturation to calculate the water activity as a function of solute weight percent, extrapolating to dilute solution concentrations relevant to describing equilibria at supersaturated vapor conditions. Water uptake data for relative humidities below about $95 \%$ are typically obtained using the humidified tandem differential mobility analyzer (HTDMA). The HTDMA measures the water uptake of a nearly monodisperse aerosol at a controlled temperature and relative humidity. The use of HTDMA data for determining solution water activities was proposed by Brechtel and Kreidenweis (2000a, b); here, we adapt their methodology to a different water activity expression. The system used in this work is described briefly here and in detail in Brechtel and Kreidenweis (2000b). Figure 1 shows the experimental set-up of the HTDMA; the unit is operated in an enclosure held at $30^{\circ} \mathrm{C}$. Aerosol is generated using a Constant Output Atomizer (TSI Model 3076), then passed through a heater, diffusion dryer, and dilution chamber to remove remaining moisture. The dry aerosol is size selected using a Differential Mobility Analyzer (DMA, TSI Model 3071A). Our results are based on a selected dry size of $100 \mathrm{~nm}$. Part of the size-selected flow is diverted to a condensation particle counter (CPC, TSI Model 3010), which gives a real-time particle concentration. The remaining flow is sent to a humidified loop where the aerosol encounters a controlled, constant relative humidity for about $2 \mathrm{~s}$ and comes to equilibrium with those conditions. The flow then is sent to a second humidified DMA, which scans through particle sizes, and a second CPC that counts the particles thus giving a size distribution for the humidified particles. The peak of the grown distribution is

(C) 2005 Author(s). This work is licensed under a Creative Commons License. 


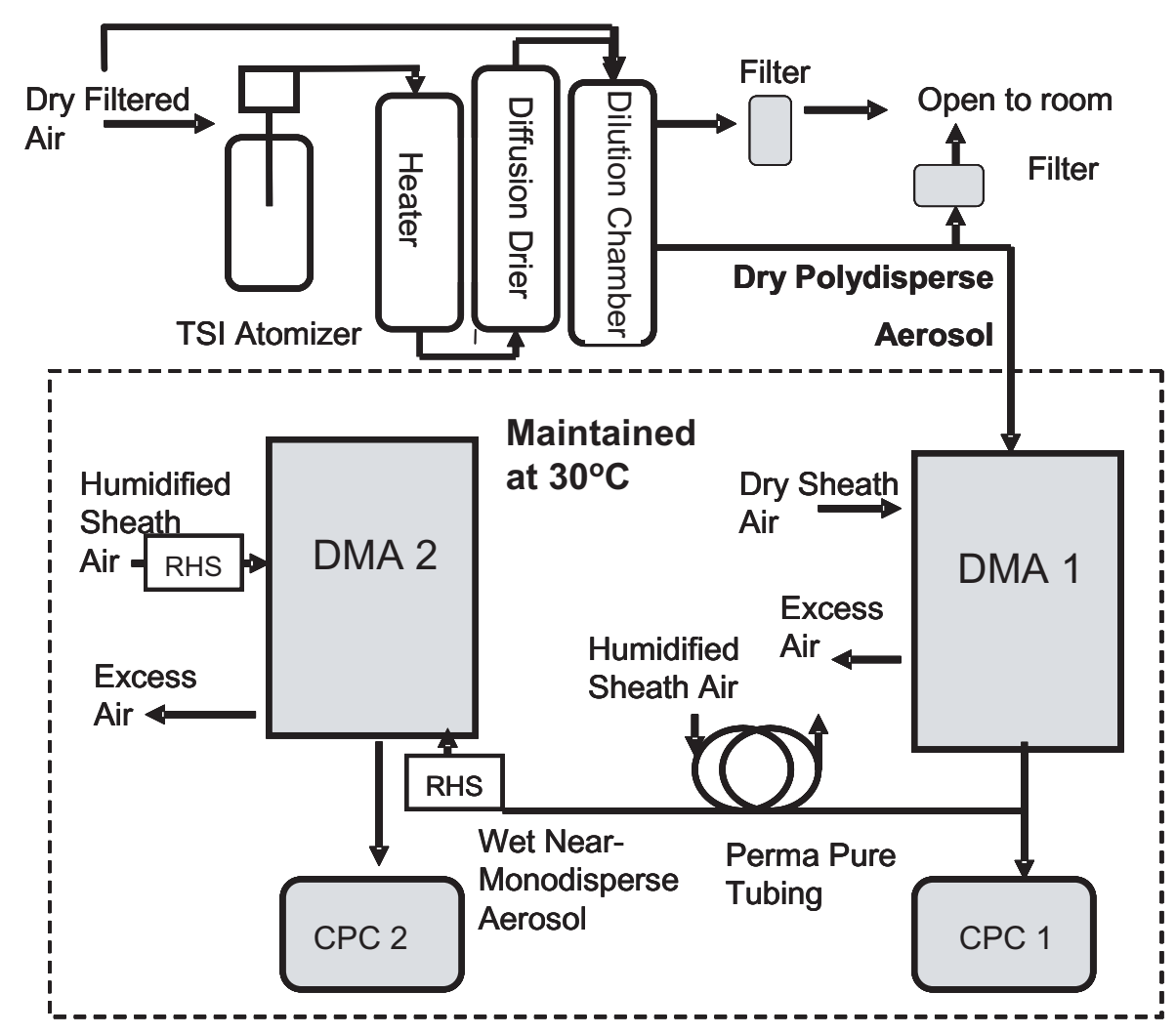

Fig. 1. Schematic of the Humidified Tandem Differential Mobility Analyzer (from Prenni et al., 2001).

determined to be the grown size at each relative humidity. The growth factor $(G F)$ is defined as

$G F(R H)=\frac{D_{w e t}(R H)}{D_{d r y}}$,

where $D_{\text {wet }}$ is the grown diameter at the selected relative humidity $(R H)$ and $D_{d r y}$ is the dry size of the particle. From the standard deviations of the DMA flows, which together with the applied voltage control particle sizing, and the uncertainties in $R H$ sensor calibration, the uncertainty in the $G F$ is estimated to be \pm 0.02 at the $95 \%$ confidence level (Carrico et al., 2005). The relative humidity sensors are accurate within $\pm 2 \%$ for $R H$ up to $95 \%$.

\section{Methodology}

\subsection{Köhler theory}

The equilibrium water vapor pressure, $p_{w}$, over a spherical solution droplet, at a particular temperature $T$, is given by the following expression:

$\frac{p_{w}}{p^{o}(T)}=s=a_{w} \exp \left(\frac{4 \sigma_{s o l} \overline{V_{w}}}{R T D_{p}}\right)=\frac{R H}{100}$
In Eq. (2), $a_{w}$ is the water activity of the solution droplet, $\sigma_{s o l}$ is the surface tension of the solution, $\overline{V_{w}}$ is the partial molar volume of water in solution, $R$ is the universal gas constant, and $D_{p}$ is the droplet size. Water activity, surface tension, and partial molar volume are all functions of composition and temperature. The ratio of the vapor pressure of water over the drop to the saturation vapor pressure of water at that temperature, $p^{o}(T)$, is known as the saturation ratio, $s$. The saturation ratio can be equated to the fractional ambient relative humidity, $R H / 100$, if the droplet is in equilibrium with its environment.

Equation (2) forms the basis of Köhler theory (Köhler, 1936), which in various forms has been used to theoretically predict the cloud condensation nucleating $(\mathrm{CCN})$ activity of simple and complex aerosols in terms of their critical supersaturations (Giebl, 2002; Kumar et al., 2003; Prenni et al., 2001; Raymond and Pandis, 2002). A plot of $s$ vs. $D_{p}$, computed for a particular assumed mass of dry solute, generally has a maximum. The saturation ratio at this maximum is the so-called critical saturation, or, more commonly, critical supersaturation, $S_{c}$, where $S$ is expressed as a percentage: $S=(s-1) \times 100$. Particles that have grown past the diameter associated with this critical supersaturation are considered to be cloud droplets. A discussion of common assumptions used to further simplify Eq. (2) is provided by Brechtel and Kreidenweis (2000a). A standard assumption is to simplify 
the calculation of the partial molar volume of water. The partial molar volume of water in solution is given by

$\overline{V_{w}}=\frac{M W_{w}}{\rho_{s o l}}\left[1+\frac{x}{\rho_{s o l}} \frac{d \rho_{s o l}}{d x}\right]$,

where $M W_{w}$ is the molecular weight of water, $\rho_{\text {sol }}$ is the density of the solution, and $x$ is the weight percent of solute. For an ideal solution, the partial molar volume of water in solution is equal to the molar volume of pure water, $M W_{w} / \rho_{w}$, also known as the volume additivity assumption. As discussed in Brechtel and Kreidenweis (2000a), the assumption of volume additivity leads to negligibly small errors in the application of Eq. (2) for common inorganic, ionic species, and will be applied in this work. Using this assumption in Eq. (2) gives

$s=a_{w} \exp \left(\frac{4 \sigma_{s o l} M W_{w}}{R T \rho_{w} D_{p}}\right)$

We note that some prior works have used $\rho_{\text {sol }}$ in place of $\rho_{w}$ in Eq. (4), which can lead to erroneously low estimates of $\overline{V_{w}}$, but the resulting error in the Kelvin term at the dilute solution concentrations near the critical supersaturation is generally negligible.

Further simplifications are directed towards the calculation of the composition-dependent water activity. The water activity may be computed from $a_{w}=\gamma_{w} y_{w}$, where $\gamma_{w}$ is the water activity coefficient in solution, a function of composition, and $y_{w}$ is the mole fraction of water in solution. It is alternately expressed as

$$
\ln \left(a_{w}\right)=\frac{-v m M W_{w} \Phi}{1000}
$$

where $\Phi$ is the molal osmotic coefficient of the solute in solution, $m$ is solution molality, and $v$ is the number of ions of solute present in solution ( $v>1$ if the solute dissociates). Thus,

$a_{w}^{-1}=\exp \left(\frac{+v m M W_{w} \Phi}{1000}\right)$.

In the early cloud physics literature, it was proposed that solution nonidealities be captured by the so-called van't Hoff factor, $i$ (Pruppacher and Klett, 1997), defined by (McDonald, 1953):

$a_{w}^{-1}=1+i \frac{n_{s}}{n_{w}}$

where $n_{s}$ and $n_{w}$ are the number of moles of solute and water in solution, respectively. The van't Hoff factor can be related to the molal osmotic coefficient as follows. A series expansion of the exponential term in Eq. (6) gives:

$a_{w}^{-1}=1+\left(\frac{\nu m M W_{w} \Phi}{1000}\right)+\frac{1}{2}\left(\frac{\nu m M W_{w} \Phi}{1000}\right)^{2}+\ldots$
Comparing Eq. (8) with Eq. (7), and recognizing that

$\frac{n_{s}}{n_{w}}=\frac{m M W_{w}}{1000}$

it can be seen that the van't Hoff factor equates to:

$i=\nu \Phi+\frac{m M W_{w}}{1000} \frac{(\nu \Phi)^{2}}{2}+\left(\frac{m M W_{w}}{1000}\right)^{2} \frac{(\nu \Phi)^{3}}{6}+\ldots$

The van't Hoff factor is thus a function of composition, particularly for more concentrated solutions, although it is often assumed constant for dilute conditions (e.g., Wise et al., 2003). If the series in Eq. (10) is truncated after the first term, then:

$a_{w}^{-1}=1+v \Phi \frac{n_{s}}{n_{w}}$.

The most frequently-applied form of Eq. (4), derived by Köhler (Pruppacher and Klett, 1997) makes the following assumptions in addition to volume additivity: the droplet contains $n_{w}$ moles of water and $n_{s}$ moles of nonvolatile solute; the moles of nonvolatile solute in solution can be computed from the initial dry particle mass, $M_{s}$, molecular weight of solute, $M W_{s}$, and the number of ions the solute dissociates into, $v$; the solution is dilute, the activity coefficient of water can be assumed to be equal to 1 ; and the surface tension of the dilute solution can be approximated by that of pure water, $\sigma_{w}$. If the solution is dilute, $\Phi \approx 1$, and

$a_{w}=\frac{n_{w}}{n_{w}+v n_{s}}$

This is the expression for water activity used in simplified Köhler theory. Under the assumptions listed above, and assuming constant properties for water surface tension and density, Eq. (2) can be formulated (Seinfeld and Pandis, 1998)

$\ln \left(\frac{p_{w}}{p^{o}}\right)=\frac{A}{D_{p}}-\frac{B}{D_{p}^{3}}$

$A=\frac{4 M W_{w} \sigma_{w}}{R T \rho_{w}} \cong \frac{0.66}{T}$

$B=\frac{6 n_{s} M_{w}}{\pi \rho_{w}} \cong \frac{3.44 \times 10^{13} v M_{s}}{M W_{s}}$,

where the units of $A$ and $D_{p}$ are microns $(\mu \mathrm{m})$, and $\mu \mathrm{m}^{3}$ for $B$.

If the initial dry particle contains insoluble material, then the number of moles of solute in solution must be computed from only the soluble portion. The necessary modification, which requires knowledge of the soluble mass fraction, is shown in Pruppacher and Klett (1997). More recently, several authors have discussed additional modifications to Köhler theory to account for other effects that may be important in atmospheric aerosols. These include mixed particles with a slightly soluble component (that is, the moles of slightly soluble component in solution depend on the amount of liquid water, which is controlled by more hygroscopic species, and thus the overall solute composition changes with $R H$ ) (Shulman et al., 1996); surfactants (Facchini et al., 
2000; Shulman et al., 1996), which lower the droplet surface tension; and wetting properties (Raymond and Pandis, 2002).

In addition to the possible inapplicability of the assumptions used to derive Eq. (13) and its modified forms, a major difficulty in applying the theory is that it requires a priori knowledge of the properties of the initial dry particle: soluble fraction, molecular weight, solute density (to estimate solute mass from the dry diameter), and the parameter $v$. Nevertheless, for many pure salts, it has been shown to be a good approximation. For pure organic species, it has been argued that $\nu=1$ for compounds that dissociate very little $(\mathrm{Ku}-$ mar et al., 2003; Prenni et al., 2001; Raymond and Pandis, 2002), but predictions based on this assumption do not always match experimental observations (Kumar et al., 2003; Raymond and Pandis, 2002). Further, although methods to extend the calculation to multiple components have been presented (Raymond and Pandis, 2003), these require values of the solubility limits and $v$ for each species.

\subsection{Use of HTDMA data to determine water activities}

In this work, we use Eq. (4) directly to compute the droplet diameter- $R H$ relationship and thus to determine $S_{c}$, the critical (maximum) equilibrium supersaturation over the droplet. We outline a method for determining $a_{w}$ as a function of solution composition from humidified tandem differential mobility analyzer measurements (Brechtel and Kreidenweis, 2000b; Prenni et al., 2001; Rader and McMurry, 1986). The HTDMA measures the hygroscopic diameter growth factor, $G F$, of particles at relative humidities less than $95 \%$, where $G F$ is defined as the ratio of the diameter in equilibrium with water vapor at the relative humidity $R H$ to the dry diameter, the latter usually measured at $R H<5 \%$.

The relationship between growth factors, composition, and water activities can be deduced as follows. Assuming volume additivity, the moles of water associated with a mole of solute at a given relative humidity can be expressed as:

$\frac{n_{w}}{n_{s}}=\left(G F^{3}-1\right) \frac{M W_{s} \rho_{w}}{M W_{w} \rho_{s}}$,

where $\rho_{s}$ is the density of the solute. By Eq. (11),

$\frac{n_{w}}{n_{s}}=v \Phi \frac{a_{w}}{1-a_{w}}$.

Substituting Eq. (14) into Eq. (15):

$\left(G F^{3}-1\right)=\nu \Phi \frac{M W_{w} \rho_{s}}{M W_{s} \rho_{w}} \frac{a_{w}}{1-a_{w}}$.

The product $v \Phi$ is not constant with composition. We assume variations can be captured by a polynomial in $a_{w}$, with adjustable parameters $a, b$, and $c$, and the molecular weights and densities can be pulled into the constants of that polynomial. The functional form thus obtained is:

$G F=\left[1+\left(a+b \cdot a_{w}+c \cdot a_{w}^{2}\right) \frac{a_{w}}{1-a_{w}}\right]^{\frac{1}{3}}$.
It can be shown that Eq. (17) has the property that, as water activity approaches 1 , the mass fraction of solute approaches zero. The resulting relationship between water activity and mole fraction of solute is shown in Eq. (18), where water activity of unity corresponds to zero mole fraction of solute and $a^{\prime}, b^{\prime}$ and $c^{\prime}$ are the polynomial coefficients multiplied by $M W_{s} \rho_{w} /\left(M W_{w} \rho_{s}\right)$ :

$\frac{n_{s}}{n_{s}+n_{w}}=\frac{1-a_{w}}{1-a_{w}+a^{\prime} \cdot a_{w}+b^{\prime} \cdot a_{w}^{2}+c^{\prime} \cdot a_{w}^{3}}$

Equation (17) is used to model the growth factors from the HTDMA data in terms of the water activity. This is the same functional form used by Dick et al. (2000), Prenni et al. (2001) and Brooks et al. (2004) except they model the $G F$ as a function of $R H$. Since $R H$, and not water activity, is measured in the HTDMA, an assumption relating $R H$ to $a_{w}$ is needed. The simplest assumption that can be made is $a_{w}=R H$. The solution water activity is equal to the relative humidity at each point if the particles are in equilibrium with the vapor and the Kelvin effect due to curvature of the droplet is negligible. For $100 \mathrm{~nm}$ particles and typical growth factors, this implies a surface tension below about $0.065 \mathrm{~J} \mathrm{~m}^{-2}$, for less than $1 \%$ error due to the Kelvin effect. Since the surface tension of many aqueous solutions is closer to that of pure water $\left(\sim 0.072 \mathrm{~J} \mathrm{~m}^{-2}\right)$, neglecting the effects of curvature can result in a few percent error in $a_{w}$. The data can be corrected for this effect by calculating the Kelvin term, Ke, for the wetted droplet size at each point. The activity of the solution is then:

$a_{w}=\frac{R H}{K e}$,

where

$K e=\exp \left(\frac{4 M W_{w} \sigma_{s o l}}{R T \rho_{w} D_{p}}\right)$.

This correction can be made either by assuming the surface tension is equal to that of pure water $\left(\sigma_{s o l}=\sigma_{w}=0.072 \mathrm{~J} \mathrm{~m}^{-2}\right)$ or using known concentration-dependent solution surface tensions.

The methodology for using HTDMA data to predict $S_{c}$ for known compounds, and for a specified dry diameter $D_{d r y}$, is as follows. Experimental data for $G F$ are fit to Eq. (17). Then a series of values of $a_{w}$ are chosen and $G F$ is computed from the fit. The masses of solute $\left(M_{s}\right)$ and water $\left(M_{w}\right)$ are then given by:

$$
\begin{aligned}
& M_{s}=D_{d r y}^{3} \frac{\pi}{6} * \rho_{s}, \\
& M_{w}=D_{d r y}^{3}\left(\frac{\pi}{6} * \rho_{s o l} *(G F)^{3}-\frac{\pi}{6} * \rho_{s}\right) .
\end{aligned}
$$

The weight percent of solute in the solution, $x$, corresponding to the water activity $a_{w}$ at which $G F$ was evaluated, is then simply

$\frac{M_{w}}{M_{s}}=\frac{100-x}{x}$ 
However, $x$ must be computed iteratively, because the density of the solution, $\rho_{s o l}$, is also a function of composition. Under the assumption of volume additivity:

$$
\rho_{\text {sol }}=\frac{1}{\frac{1-\frac{x}{100}}{\rho_{w}}+\frac{\frac{x}{100}}{\rho_{s}}} .
$$

The water activity data as a function of $x$ that are obtained by application of this methodology are then used in Eq. (4) to compute values on the supersaturation-droplet diameter curve for any choice of dry diameter. The maximum is identified as the critical supersaturation for that dry particle size.

We note that other methods have been proposed for relating hygroscopic growth, as measured by the HTDMA, to critical supersaturation. Recently, Rissler et al. (2004) have reviewed these and present the approach for estimating the number of soluble ions contained in a particle and the soluble volume fraction. These parameters can then be used in appropriate versions of the classical Köhler theory equations to predict critical supersaturation; Rissler et al. (2004) found good agreement between measured and predicted CCN concentrations using this method. The spirit of their approach is similar to that outlined here, but uses $G F$ at only one $R H$ for parameter estimation, and thus assumes the shape of the $a_{w}-G F$ relationship that is here fitted to the more general Eq. (17).

\subsection{Sources of uncertainty}

Application of Eqs. (21) through (24) in the methodology outlined above requires selection of a value for the density of the dry solute. This choice determines the value of $x$ associated with a particular growth factor. However, since $G F$ expresses the ratio of wet to dry particle volume, and not mass, the $a_{w}$-GF relationship determined from the HTDMA data does not depend on the choice of $\rho_{s}$, and its extrapolation to the dilute conditions at the critical supersaturation is also independent of the choice of dry density. If selfconsistent choices of $\rho_{s}$ are used to determine both $a_{w}(x)$ and to compute Köhler curves via Eq. (4), the predicted $S_{c}$ and wet droplet size are independent of the choice of dry density. This implies that the method could be applied to unknown compounds or mixtures, with an arbitrary choice of $\rho_{s}$, to yield satisfactory predictions of the critical supersaturation. However, comparison of $a_{w}(x)$ for a particular compound obtained from this method with $a_{w}(x)$ for that species obtained by other methods will of course depend on the choice of $\rho_{s}$.

Although the determination of the critical supersaturation is not sensitive to the choice of dry particle density used, it does rely on accurate determination of the dry particle volume. The DMA selects size using an electrical mobility diameter, which assumes a spherical shape. However, many substances, when dried, will have a crystalline structure. This non-spherical structure leads to a larger drag and a larger electrical mobility diameter, and therefore the mobility diameter is larger than the volume equivalent diameter. When the particle takes up water it will preferentially adsorb water at the corners of the non-spherical particle and transform to a nearly spherical shape (Mikhailov et al., 2004). Since the dry volume is actually smaller than it appears in the DMA, there is an apparent underestimation of the water uptake. Shape factors are used to correct HTDMA data for the overestimation of dry volume equivalent diameter. The growth factor including the shape factor, $\chi$, where $\chi>1$ is

$G F=\frac{D_{p}(R H)}{D_{d r y}} \frac{\chi C_{c}\left(D_{d r y}\right)}{C_{c}\left(D_{c o r r}\right)}$,

where $C_{c}$ is the Cunningham correction factor, $D_{d r y}$ refers to the mobility diameter, and $D_{\text {corr }}$ refers to the volume equivalent (corrected) diameter (Gysel et al., 2002). Sodium chloride has a cubic structure when dry; application of a shape factor of 1.08 has been shown to be appropriate for this compound (Brechtel and Kreidenweis, 2000b; Rader and McMurry, 1986). At the altitude of our laboratory, application of equation (25) to $\mathrm{NaCl}$ particles with mobility diameters of $100 \mathrm{~nm}$ results in a correction factor of 1.04 to experimental values of $G F$. For ammonium sulfate, the dry particles are assumed to be spherical, which has been previously determined to be a good assumption. For other species, it is possible that the dried particles are non-spherical. However, the appropriate shape factor is not generally known, and $\chi=1$ is commonly assumed. Uncertainty due to this assumption is examined in the sensitivity studies section.

Some species, such as ammonium nitrate, are known to exist in several solid and liquid-like states depending on the temperature, pressure, humidity, and purity (Mikhailov et al., 2004). This chemical restructuring can take place within the HTDMA, giving rise to errors in dry particle size on the order of several nanometers. It has also been shown that some semi-volatile species evaporate in the HTDMA between the selection of the dry size in DMA1 and the measuring at DMA2 (Prenni et al., 2001); the same phenomenon confounds interpretation of water activity data from the electrodynamic balance (Peng et al., 2001). Although evaporative effects are accounted for experimentally as far as possible, the degree of evaporation may be a function of the relative humidity, resulting in additional uncertainty in the dry particle sizing (Mikhailov et al., 2004).

\section{Application to selected ionic species}

In this section, we apply the proposed methodology to HTDMA data from our laboratory for ammonium sulfate and sodium chloride particles, and compare the derived $a_{w}(x)$ relationships with published data and models. We also predict the critical supersaturations for both particle types, and compare predictions with simplified Köhler theory and with published experimental $\mathrm{CCN}$ data. 


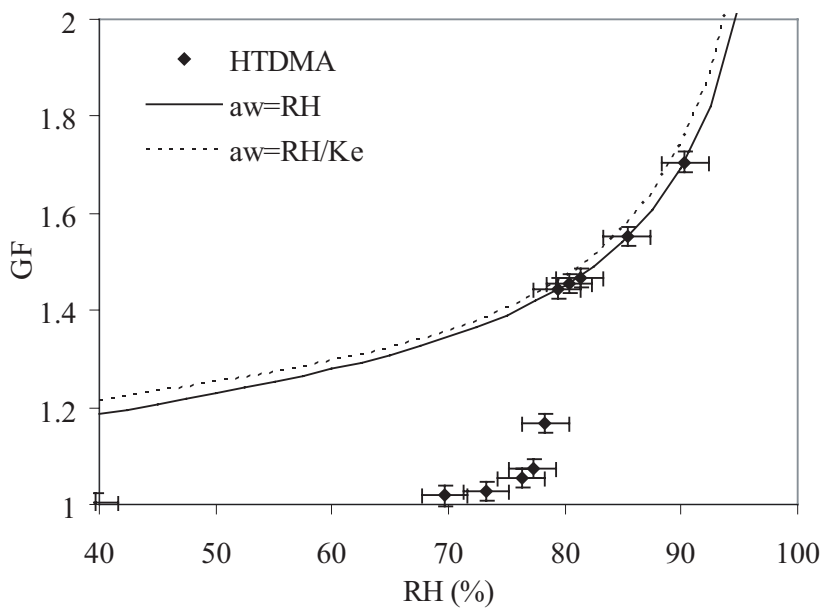

Fig. 2. HTDMA data for $100 \mathrm{~nm}$ ammonium sulfate particles. Curves are the fit to the data using the uncorrected data $\left(a_{w}=R H\right)$ and removing the Kelvin effect $\left(a_{w}=R H / \mathrm{Ke}\right)$.

\subsection{Ammonium sulfate}

\subsubsection{Water activity}

Figure 2 shows HTDMA data for $100 \mathrm{~nm}$ dry ammonium sulfate particles. The particles were generated by atomization of a 1 weight percent solution, and dried to $R H<5 \%$ before sampling and size selection. The indicated uncertainties in $G F$ and $R H$ are 0.02 and 2\%, respectively (Carrico et al., 2005). The curves in Fig. 2 indicate the fit by Eq. (17) for two cases: assuming $a_{w}=R H$ and including the Kelvin correction, assuming a constant $\sigma_{s o l}=0.072 \mathrm{~J} \mathrm{~m}^{-2}$. The fits use only data obtained at $R H$ values above the deliquescence point $(R H=79 \%)$. Fit coefficients to Eq. (17) are provided in Table 1; fitting was performed without consideration of experimental uncertainties. Figure 3 illustrates the predicted relationship, from both fit curves, between drop size and the equilibrium percent supersaturation, $S ; S_{c}$ is indicated by the point defining the maximum of each curve. In the calculations of $S_{c}$ shown in Fig. 3, the variation of surface tension with composition was ignored, and $\sigma_{s o l}$ was again set equal to $\sigma_{w}=0.072 \mathrm{~J} \mathrm{~m}^{-2}$.

The estimated water activities, expressed as functions of solution weight percent, are shown in Figs. $4 \mathrm{a}$ and b, together with estimates from published data or models. The Tang and Munkelwitz (1994) polynomials for $a_{w}(x)$ were based on data from an electrodynamic balance (EDB), which exposes a supermicron particle to various relative humidities and measures the mass increase due to water uptake. Those authors mapped out water contents for the crystallization (metastable) branch of the ammonium sulfate curve, whereas our HTDMA experiments always started with dry particles. As with the HTDMA method, it is difficult to control the experimental $R H$ in the EDB at $R H>95 \%$, so their polynomial

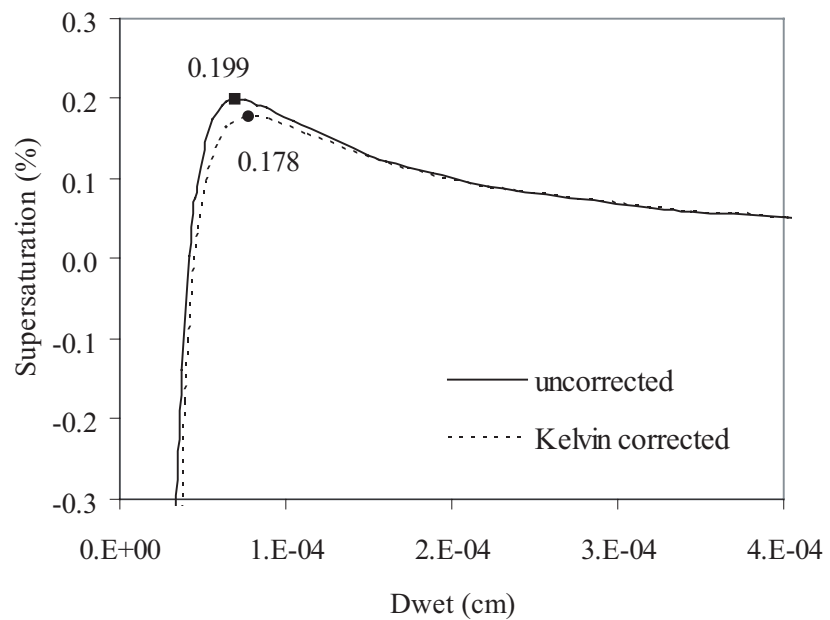

Fig. 3. Köhler curves for $100 \mathrm{~nm}$ ammonium sulfate dry particle, using the uncorrected and Kelvin-corrected HTDMA-derived water activities.

fit is less constrained for dilute solutions. Low (1969) used activity and osmotic coefficients reported by Lange (1961) to determine water activity over a range of concentrations, which were reported as values of the van't Hoff factor as functions of solution composition. The Wise et al. (2003) relationship is computed from their estimate of a constant van't Hoff factor, using water activities derived from vapor pressure measurements for moderately dilute solutions. The AIM model is described by Clegg et al. (1998a) and accessible online at http://mae.ucdavis.edu/wexler/aim. Because of the extensive experimental data and model evaluations it incorporates, in these comparisons we consider the AIM estimates of solution water activities to be the most accurate.

Water activity as expressed by simplified Köhler theory (Eq. 12, with $v=3$ ) is also shown in Figs. 4a and b. The water activity predicted by simplified Köhler theory is significantly different from the other estimates. This is not surprising, because $v=3$ has been shown to be an overestimation of the dissociation (Gerber et al., 1977; Kumar et al., 2003). The water activities from the Kelvin-corrected case derived from HTDMA data match the predictions from the AIM model and Tang and Munkelwitz (1994) very well, while the estimates from the Wise et al. (2003) model are somewhat lower.

In the dilute limit, the activity coefficient of the solute can be expressed by the limiting Debye-Hückel theory, leading to the following expression for the water activity:

$\ln a_{w}=\frac{0.509}{3} \frac{v M W_{w}}{1000} m^{3 / 2}-\frac{v M W_{w}}{1000} m$

where $m$ is the molality of the solution, moles $(\mathrm{kg} \text { water })^{-1}$. As can be seen in Fig. 4b, all models except the Köhler assumption (Eq. 12) vary significantly from the predictions of Eq. (26). However, the solution weight percentages computed for the range of $S_{c}$ examined here $(0.3 \%-1.0 \%)$ vary 
Table 1. Fitting constants for $G F-a_{w}$ relationship, parameterization constants for CCN activity, and deduced $\nu$ s for ammonium sulfate and sodium chloride. See text for full explanation.

\begin{tabular}{lllllll}
\hline Species and Model & $\mathrm{a}$ & $\mathrm{b}$ & $\mathrm{c}$ & $\alpha$ & $\beta$ & $v$ \\
\hline Ammonium sulfate; uncorrected & 1.71845 & -2.04960 & 0.69443 & 34.0425 & 26.1487 & 1.36 \\
Ammonium sulfate; Kelvin corrected & 2.42848 & -3.85261 & 1.88159 & 31.4475 & “ & 1.72 \\
Sodium chloride; uncorrected & 3.89243 & -4.49667 & 1.62110 & 24.2239 & 21.3277 & 1.37 \\
Sodium chloride; Kelvin corrected & 4.83257 & -6.92329 & 3.27805 & 23.0149 & “ & 1.59 \\
Sodium chloride; Kelvin and shape corrected & 5.78874 & -8.38172 & 3.9265 & 22.2781 & “ & 1.96 \\
\hline
\end{tabular}

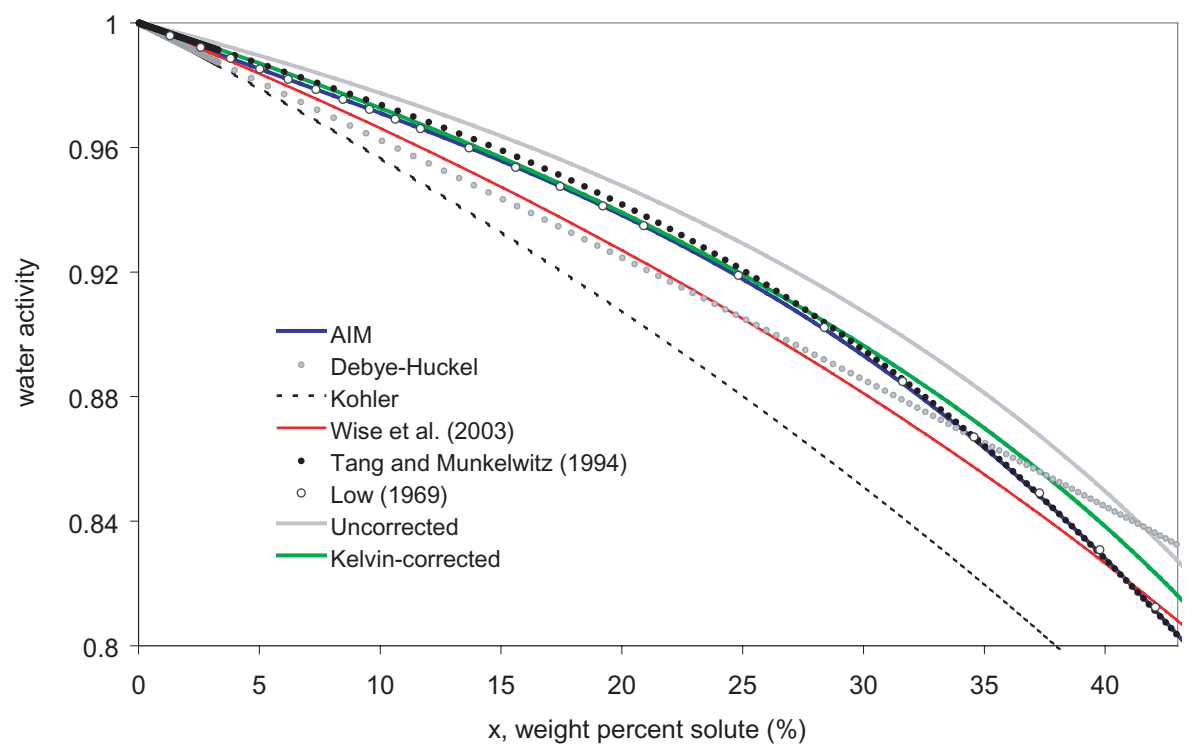

(a)

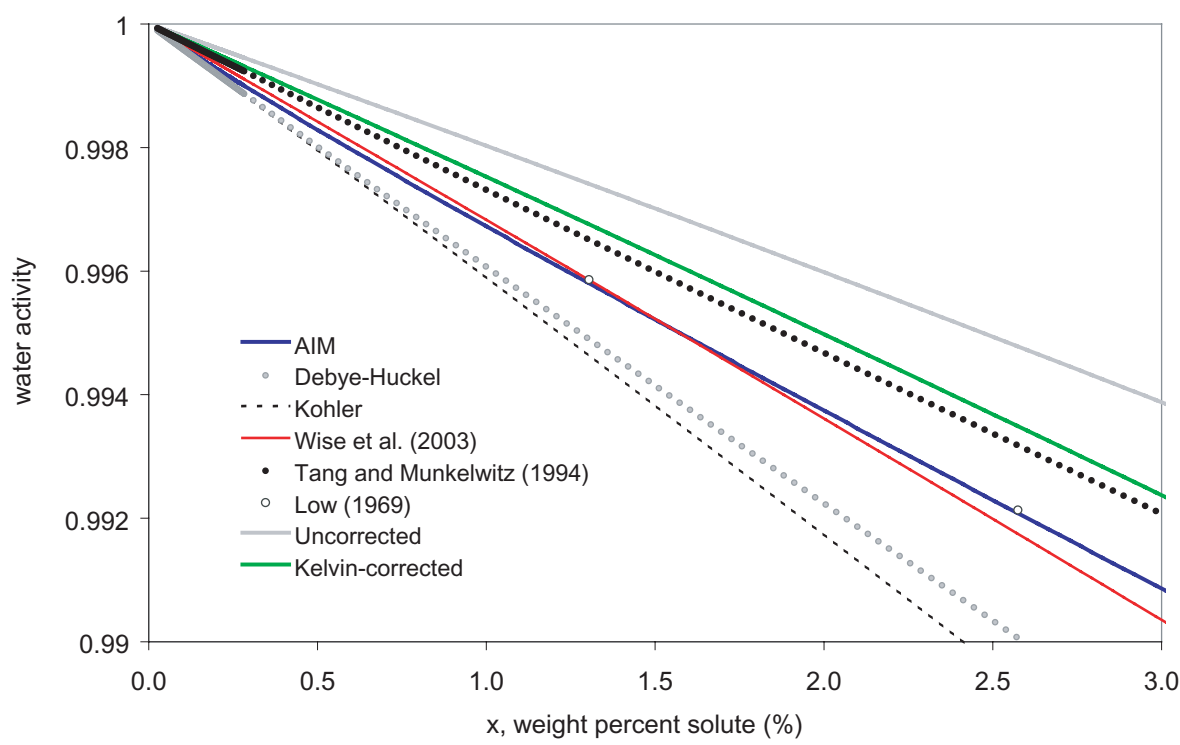

(b)

Fig. 4. (a) Water activity as a function of ammonium sulfate weight percent. Corrected and Kelvin corrected: this study. Other relationships shown are from Tang and Munkelwitz (1994); Wise et al. (2003); the AIM Model (Clegg et al., 1998a); Low et al. (1969). Köhler: Eq. (12) with $\nu=3$ assumed; and the Debye-Hückel limiting law (Eq. 26). (b) Water activity as a function of ammonium sulfate weight percent in the dilute limit. 


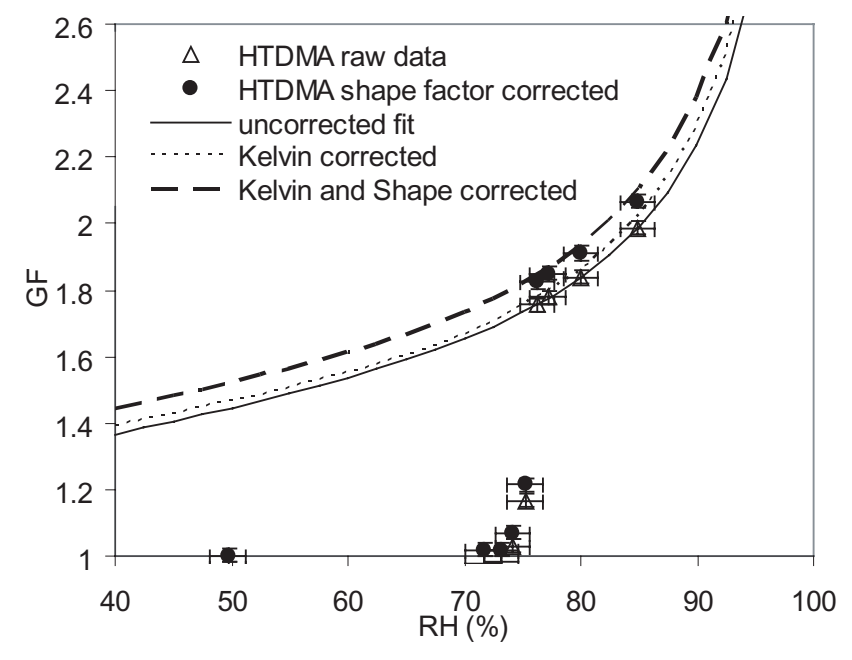

Fig. 5. Growth factor data for sodium chloride: triangles, raw data; closed circles: after shape factor correction. Curves represent the fits to the data for the uncorrected, Kelvin-corrected, and shapeand Kelvin-corrected cases.

from about $0.5 \%$ to $3 \%$, well outside the range of applicability of the Debye-Hückel limiting law.

\subsubsection{Critical dry diameters}

In Table 2, we compare predictions of critical supersaturations using the various $a_{w}(x)$ relationships, and examine the agreement with experimental observations (Corrigan and Novakov, 1999; Giebl, 2002; Raymond and Pandis, 2002; Kumar et al., 2003). The calculations use Eq. (4) with $\sigma_{s o l}=\sigma_{w}=0.072 \mathrm{~J} \mathrm{~m}^{-2}$, unless indicated otherwise, and $T=298 \mathrm{~K}$. To conform to the typical experimental configurations, we select $S_{c}$ of $0.3 \%, 0.4 \%, 0.8 \%$ and $1 \%$ and compute the dry diameters ("critical dry diameter") that yield these critical supersaturations. The uncorrected HTDMA data consistently give the largest predicted critical dry diameters, as expected from the water activities shown in Fig. 4. The range in predicted critical dry diameter for each supersaturation is shown in the last row of Table 2. The predictions from the HTDMA method, and the overall variation produced by the various estimates, are within the experimental uncertainties reported by Raymond and Pandis (2002).

\subsection{Sodium chloride}

\subsubsection{Water activity}

The analyses of HTDMA data described above for ammonium sulfate have been repeated for sodium chloride. HTDMA data and fits for this species are shown in Fig. 5 and fitting constants are listed in Table 1. As discussed above, sodium chloride has the added complication that when aerosol is generated and dried it forms a cubic shape which must be corrected for in the size selection by the DMA. The

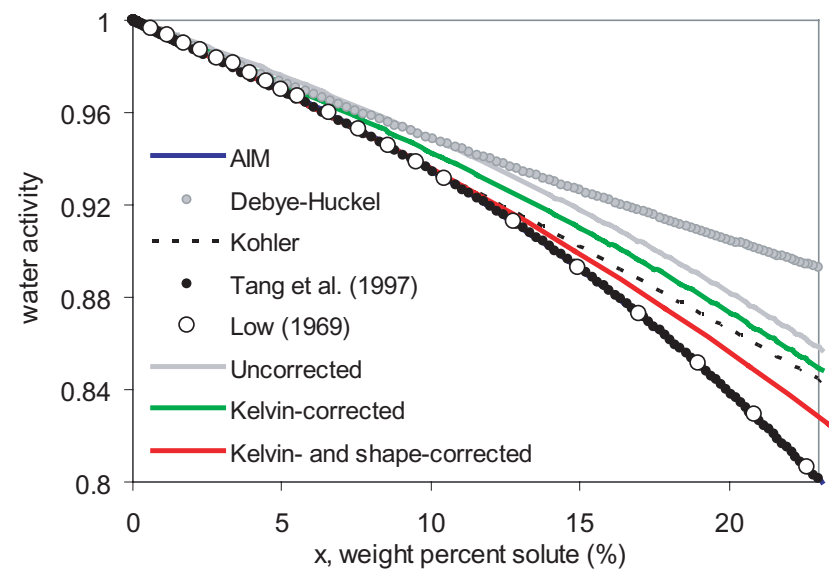

Fig. 6. Water activity as a function of sodium chloride weight percent. Uncorrected, Kelvin-corrected, and shape- and Kelvincorrected cases: this study, as described in the text. Other relationships shown are from Tang et al. (1997); the AIM Model (Clegg et al., 1998b); and Low et al. (1969), Köhler: Eq. (12) with $\nu=2$ assumed; and the Debye-Hückel limiting law (Eq. 26).

water activity is then modeled in three ways: (1) from uncorrected HTDMA data; (2) from Kelvin-corrected HTDMA data; and (3) from Kelvin- and shape factor-corrected HTDMA data. Method (3) is expected to give the most accurate results, since without the shape factor correction, the solute mass is overestimated and the growth factors underestimated.

Figure 6 shows $a_{w}(x)$ computed from the HTDMA data, compared with relationships due to Tang et al. (1997), Low (1969), the AIM model (Clegg et al., 1998b; http: //mae.ucdavis.edu/wexler/aim), and simplified Köhler theory with $\nu=2$. The Kelvin- and shape-corrected HTDMA data are in good agreement with the Tang et al. (1997) and AIMderived relationships over the entire range, while the other methods give substantially different estimates for $R H<90 \%$.

\subsubsection{Critical dry diameters}

In Table 3 we compare critical dry diameters predicted from our method at several water supersaturations with observations reported in the literature. Experimental results are from Corrigan and Novakov (1999), Giebl et al. (2002) and Raymond and Pandis (2002). Water activities derived from HTDMA data that have not been corrected for the shape factor give critical dry diameters that are too large. This is due to the error in determining the solute volume when computing the growth factor, making the particles appear less hygroscopic than they truly are. When the HTDMA data are processed using the shape factor and correcting for the Kelvin effect, the resulting critical dry diameters match reported experimental data, as well as predictions from Köhler theory, very well. As indicated by the close agreement between the water activities seen in Fig. 6, calculations using the AIM and Tang et al. (1997) relationships are very similar to those using water 
Table 2. Comparison of various predicted critical dry diameters and available observations for ammonium sulfate.

\begin{tabular}{|c|c|c|c|c|c|}
\hline & $\begin{array}{l}\text { Critical Diameter } \\
(\mathrm{nm}) \\
S_{c}=0.3 \%\end{array}$ & $\begin{array}{l}\text { Critical Diameter } \\
(\mathrm{nm}) \\
S_{c}=0.4 \%\end{array}$ & $\begin{array}{l}\text { Critical Diameter } \\
(\mathrm{nm}) \\
S_{c}=0.8 \%\end{array}$ & $\begin{array}{l}\text { Critical Diameter } \\
(\mathrm{nm}) \\
S_{c}=1 \%\end{array}$ & Reference/Notes \\
\hline $\begin{array}{l}\text { Raymond and Pandis (2002), } \\
\text { experimental observation }\end{array}$ & $66 \pm 13$ & & & $26 \pm 4$ & Raymond and Pandis (2002) \\
\hline $\begin{array}{l}\text { Corrigan and Novakov (1999), } \\
\text { experimental observation }\end{array}$ & & $51 \pm 8$ & $30 \pm 5$ & & Corrigan and Novakov (1999) \\
\hline $\begin{array}{l}\text { Giebl et al. (2002), } \\
\text { experimental observation }\end{array}$ & & $\begin{array}{l}52.5 \\
\left(S_{c}=0.42 \%\right)\end{array}$ & & $\begin{array}{l}29.1 \\
\left(S_{c}=1.08 \%\right)\end{array}$ & Giebl et al. (2002) \\
\hline $\begin{array}{l}\text { Kumar et al. (2003), } \\
\text { experimental observation }\end{array}$ & $67 \pm 10$ & $59 \pm 9$ & & & Kumar et al. (2003) \\
\hline $\begin{array}{l}\text { This work, fit uncorrected } \\
\text { for Kelvin effects }\end{array}$ & $\begin{array}{l}75.9 \\
(76.7)^{a}\end{array}$ & $\begin{array}{l}62.6 \\
(60.6)^{b}\end{array}$ & 39.3 & $\begin{array}{l}33.8 \\
(32.1)^{b}\end{array}$ & \\
\hline $\begin{array}{l}\text { This work, fit corrected } \\
\text { for Kelvin effects }\end{array}$ & $\begin{array}{l}70.5 \\
(71.2)^{a}\end{array}$ & $\begin{array}{l}58.1 \\
(56.2)^{b}\end{array}$ & 36.5 & $\begin{array}{l}31.4 \\
(29.9)^{b}\end{array}$ & \\
\hline $\begin{array}{l}\text { This work, fit corrected for } \\
\text { Kelvin and surface tension effects }\end{array}$ & 69.7 & 57.5 & 36.3 & 31.2 & $\begin{array}{l}\text { Surface tension estimated } \\
\text { from Pruppacher and Klett (1997) }\end{array}$ \\
\hline $\begin{array}{l}\text { Standard Köhler Theory, } \\
\text { Eq. (4) }\end{array}$ & 59.3 & 49.0 & 30.9 & 26.6 & $\begin{array}{l}\text { Water activity } \\
\text { from Eq. (12) }\end{array}$ \\
\hline $\begin{array}{l}\text { Raymond and Pandis (2002), } \\
\text { theoretical calculation }\end{array}$ & 61 & & & 27 & Raymond and Pandis (2002) \\
\hline $\begin{array}{l}\text { Corrigan and Novakov (1999), } \\
\text { predicted by Köhler Theory }\end{array}$ & & 50 & 31 & & Corrigan and Novakov (1999) \\
\hline $\begin{array}{l}\text { Brechtel and Kreidenweis (2000a), } \\
\text { theoretical calculation }\end{array}$ & $\begin{array}{l}70 \\
\left(S_{c}=0.295 \%\right)\end{array}$ & & & & Brechtel and Kreidenweis (2000a) \\
\hline $\begin{array}{l}\text { Kumar et al. (2002), } \\
\text { standard Köhler theory }\end{array}$ & 59.4 & 49.0 & & & Kumar et al. (2002) \\
\hline $\begin{array}{l}\text { Kumar et al. (2002), using } \\
\text { Clegg et al. (1996) water activity }\end{array}$ & 63.2 & 52.6 & & & Kumar et al. (2002) \\
\hline $\begin{array}{l}\mathrm{a}_{w} \text { from Tang and Munkelwitz (1994) } \\
\sigma_{\text {sol }}=\text { constant }=0.072 \mathrm{~J} / \mathrm{m}^{2}\end{array}$ & 68.2 & 56.4 & 35.7 & 30.8 & Tang and Munkelwitz (1994) \\
\hline $\begin{array}{l}\mathrm{a}_{w} \text { from AIM model; } \\
\sigma_{\text {sol }}=\text { constant }=0.072 \mathrm{~J} / \mathrm{m}^{2}\end{array}$ & 62.9 & 52.3 & 33.5 & 29.1 & Clegg et al. (1998a) \\
\hline $\begin{array}{l}\mathrm{a}_{w} \text { from Debye-Huckel limiting law; } \\
\sigma_{\text {sol }}=\text { constant }=0.072 \mathrm{~J} / \mathrm{m}^{2}\end{array}$ & 59.9 & 49.5 & 31.4 & 27.1 & \\
\hline $\begin{array}{l}\mathrm{a}_{w} \text { from Wise et al. }(2004) ; \\
\sigma_{\text {sol }}=\text { constant }=0.072 \mathrm{~J} / \mathrm{m}^{2}\end{array}$ & 64.7 & 53.4 & 33.7 & 29.0 & Wise et al. (2004) \\
\hline $\begin{array}{l}\text { Range in predicted } \\
\text { critical dry diameters }\end{array}$ & $\begin{array}{l}75.9-59.3 \\
68 \pm 8\end{array}$ & $\begin{array}{l}62.6-49 \\
56 \pm 7\end{array}$ & $\begin{array}{l}39.3-31 \\
35 \pm 4\end{array}$ & $\begin{array}{l}33.8-27 \\
30 \pm 3\end{array}$ & \\
\hline
\end{tabular}

${ }^{a}$ Parenthetical values are computed at $S_{c}=0.295 \%$, for comparison with Brechtel and Kreidenweis (2000a).

${ }^{b}$ Parenthetical values are computed at $S_{c}=0.42 \%$ or $1.08 \%$, for comparison with Giebl et al. (2002). 
Table 3. Comparison of various predicted critical dry diameters and available observations for sodium chloride ${ }^{a}$.

\begin{tabular}{|c|c|c|c|c|c|}
\hline & $\begin{array}{l}\text { Critical Diameter } \\
(\mathrm{nm}) \\
S_{c}=0.3 \%\end{array}$ & $\begin{array}{l}\text { Critical Diameter } \\
(\mathrm{nm}) \\
S_{c}=0.4 \%\end{array}$ & $\begin{array}{l}\text { Critical Diameter } \\
(\mathrm{nm}) \\
S_{c}=0.8 \%\end{array}$ & $\begin{array}{l}\text { Critical Diameter } \\
(\mathrm{nm}) \\
S_{c}=1 \%\end{array}$ & Reference/Notes \\
\hline $\begin{array}{l}\text { Raymond and Pandis (2002), } \\
\text { experimental observation }\end{array}$ & $48 \pm 10$ & & & $19 \pm 3$ & Raymond and Pandis (2002) \\
\hline $\begin{array}{l}\text { Corrigan and Novakov (1999), } \\
\text { experimental observation }\end{array}$ & & $40 \pm 6$ & & & Corrigan and Novakov (1999) \\
\hline $\begin{array}{l}\text { Giebl et al. (2002), } \\
\text { experimental observation }\end{array}$ & $\begin{array}{l}71.4 \\
\left(S_{c}=0.22 \%\right)\end{array}$ & $\begin{array}{l}34.0 \\
\left(S_{c}=0.58 \%\right)\end{array}$ & & & Giebl et al. (2002) \\
\hline $\begin{array}{l}\text { This work, fit } \\
\text { uncorrected for Kelvin effects }\end{array}$ & $\begin{array}{l}54.2 \\
(66.7)\end{array}$ & $\begin{array}{l}44.6 \\
(34.7)\end{array}$ & 28.1 & 24.2 & \\
\hline $\begin{array}{l}\text { This work, fit } \\
\text { corrected for Kelvin effects }\end{array}$ & $\begin{array}{l}51.4 \\
(63.2)\end{array}$ & $\begin{array}{l}42.4 \\
(33.1)\end{array}$ & 26.7 & 23.0 & \\
\hline $\begin{array}{l}\text { This work, fit corrected } \\
\text { for Kelvin and shape effects }\end{array}$ & $\begin{array}{l}49.5 \\
(60.9)\end{array}$ & $\begin{array}{l}40.8 \\
(31.8)\end{array}$ & 25.7 & 22.1 & correction factor $=1.04$ \\
\hline $\begin{array}{l}\text { Standard Köhler Theory, } \\
\text { Eq. (4) }\end{array}$ & 48.4 & 40.0 & 25.2 & 21.7 & $\begin{array}{l}\text { Water activity } \\
\text { from Eq. (12) }\end{array}$ \\
\hline $\begin{array}{l}\text { Raymond and Pandis (2002), } \\
\text { theoretical calculation }\end{array}$ & 51 & & & 23 & Raymond and Pandis (2002) \\
\hline $\begin{array}{l}\text { Corrigan and Novakov (1999), } \\
\text { predicted by Köhler Theory }\end{array}$ & & 41 & 26 & & Corrigan and Novakov (1999) \\
\hline $\begin{array}{l}\text { Brechtel and Kreidenweis (2000), } \\
\text { theoretical calculation }\end{array}$ & $\begin{array}{l}70 \\
\left(S_{c}=0.20 \%\right)\end{array}$ & $\begin{array}{l}40 \\
\left(S_{c}=0.47 \%\right)\end{array}$ & & & Brechtel and Kreidenweis (2000) \\
\hline $\begin{array}{l}\mathrm{a}_{w} \text { from Tang et al. }(1997) \\
\sigma_{\text {sol }}=\text { constant }=0.072 \mathrm{~J} / \mathrm{m}^{2}\end{array}$ & 47.9 & 39.6 & 25.0 & 21.6 & $\begin{array}{l}\text { Activity and density } \\
\text { from Tang et al. (1997) }\end{array}$ \\
\hline $\begin{array}{l}\mathrm{a}_{w} \text { from AIM model; } \\
\sigma_{\text {sol }}=\text { constant }=0.072 \mathrm{~J} / \mathrm{m}^{2}\end{array}$ & 49.3 & 40.8 & 25.8 & 22.3 & Clegg et al. (1998b) \\
\hline $\begin{array}{l}\mathrm{a}_{w} \text { from Debye-Huckel limiting law; } \\
\sigma_{\text {sol }}=\text { constant }=0.072 \mathrm{~J} / \mathrm{m}^{2}\end{array}$ & 49.0 & 40.5 & 25.7 & 22.2 & \\
\hline $\begin{array}{l}\text { Range in predicted } \\
\text { critical dry diameters }\end{array}$ & $\begin{array}{l}54.2-47.7 \\
51 \pm 3\end{array}$ & $\begin{array}{l}44.6-39.4 \\
42 \pm 3\end{array}$ & $\begin{array}{l}28.1-24.8 \\
27 \pm 2\end{array}$ & $\begin{array}{l}24.2-21.3 \\
23 \pm 1\end{array}$ & \\
\hline
\end{tabular}

${ }^{a}$ Parenthetical values are computed at $S_{c}$ corresponding to those reported by Giebl et al. (2002).

activities derived from HTDMA data corrected for the Kelvin and shape factors. The overall range in predicted critical dry diameter is shown in the last row of the table. The predictions, including those using the least-accurate water activities derived from uncorrected HTDMA data, are within or close to the range of experimental observations; the spread in predicted diameters at a given supersaturation is generally smaller than the uncertainty ranges reported by Raymond and Pandis (2002) and Corrigan and Novakov (1999).

\section{Sensitivity studies}

\subsection{Sensitivity to shape factor}

We next examine how unknown shape factors in the HTDMA data ultimately affect the predicted critical dry diameters. As the shape factor increases, the predicted critical dry diameters for a selected supersaturation will decrease. Figure 7 shows the magnitude of this change for sodium chloride particles, where the correction including shape factor and Cunningham correction factors, as shown in Eq. (25), is known to be 1.04. As the correction factor used to process the HTDMA data is increased from 1 to 1.16 , the spread of the critical 


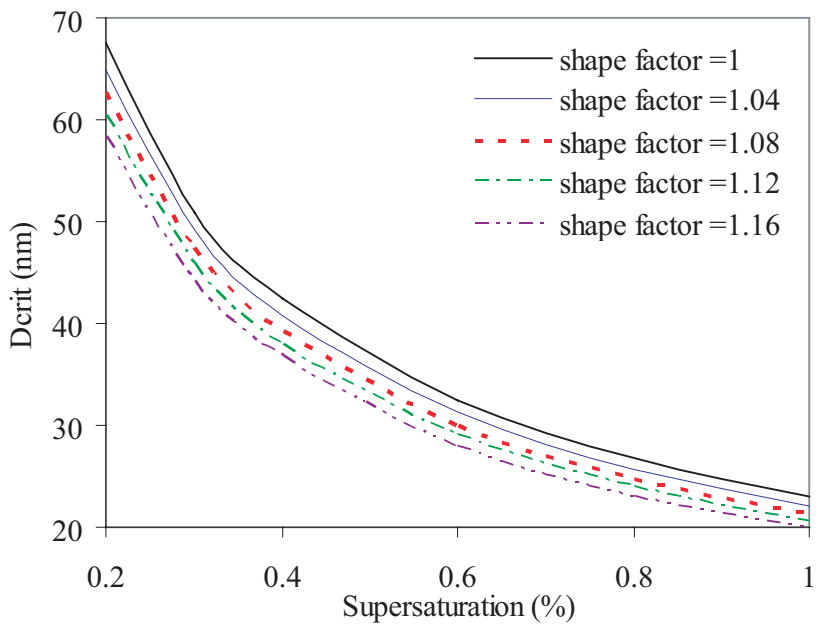

Fig. 7. Variation of critical dry diameter, as a function of percent supersaturation, with total shape correction factor (see Eq. (25)). Calculations use sodium chloride HTDMA data, as described in the text.

dry diameters is nearly $7 \mathrm{~nm}$ at $0.3 \%$ supersaturation but decreases as the supersaturation increases to about $3 \mathrm{~nm}$ at $1 \%$ supersaturation; both represent about a $14 \%$ change. Thus at higher supersaturations, the absolute error will be quite small, even for correction factors as large as 1.16. From Fig. 7 we may infer that over-prediction of the size of the critical dry diameter, compared with experimental observations, could be improved if a correction factor greater than one were applied to the HTDMA data used to construct the water activity curves. Conversely, if predicted critical dry diameters are not larger than the experimental results, we can infer that assuming a shape factor equal to one is an acceptable approximation. This appears to be the case for ammonium sulfate.

We note that, in some locations, a significant fraction of the particles may consist of slightly-hygroscopic chain agglomerates. Shape factors for such particles may be larger than the range explored in Fig. 7, and thus substantial errors in estimated critical dry diameters would be likely if this approach were applied to them.

Figure 7 can also be used to examine sensitivity of predictions to uncertainty in the HTDMA data. A correction factor of 1.02 is equivalent to a $2 \%$ overestimate of diameter ratios. This $2 \%$ error in the GF yields errors in the critical dry diameters of $0.5-1.5 \mathrm{~nm}$, or approximately $2 \%$.

\subsection{Sensitivity to assumed dry density}

As discussed in Sect. 2.3, if the density of small particles is not the same as the bulk density of the substance, or if a species of unknown density is studied, the critical dry diameters can still be predicted with the same accuracy since the method essentially extrapolates the volume ratios to dilute conditions, and not the mass ratios. That is, the critical

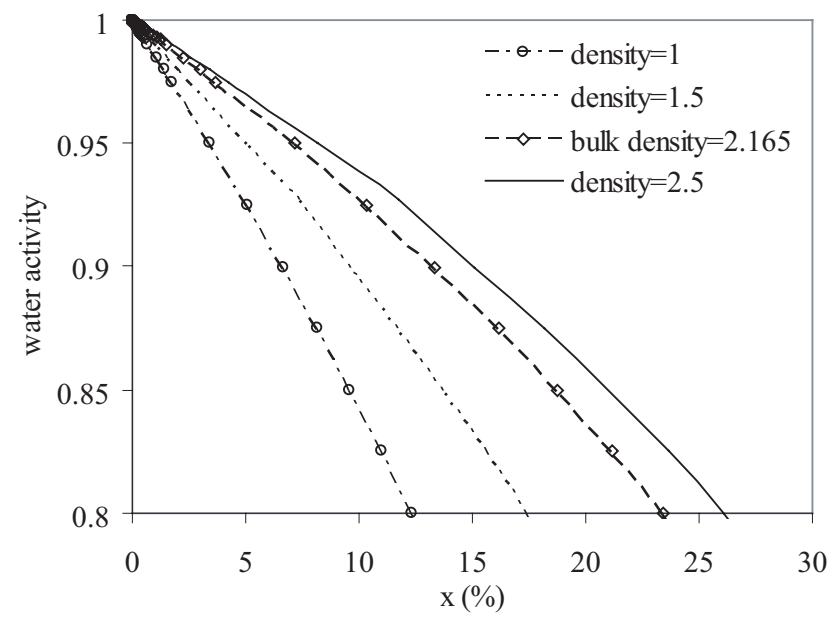

Fig. 8. Water activity as a function of sodium chloride weight percent in solution, assuming different dry densities in the data processing. Densities are given in $\mathrm{kg} \mathrm{m}^{-3} \times 10^{-3}$.

supersaturations are predicted from extrapolation of the $a_{w^{-}}$ $G F$ relationship, which is fitted without recourse to a density assumption. Thus the Köhler curves do not depend on the assumed value of the dry density. This result suggests that, for ambient aerosols with unknown density, a surrogate density could be assumed and representative Köhler curves obtained by extrapolation of GF data. This hypothesis needs to be evaluated with appropriate experiments.

However, the water activity as a function of solute weight percent, $a_{w}(x)$, derived from the HTDMA data will be different for different assumed densities, as shown in Fig. 8 for sodium chloride. Thus, for calculations where water activity must be computed for a specified mass fraction of a species, for example, for mixed particles, knowledge of the correct density is still required to deduce $a_{w}(x)$ relationships applicable to those cases.

\subsection{Sensitivity to surface tension}

Estimates of critical dry diameters are reported in Tables 2 and 3 for HTDMA data processed using two disparate assumptions: no Kelvin term (essentially, low surface tension compared with that of water), and Kelvin effect corresponding to the surface tension of pure water. The differences in predictions indicated in the Tables provide some guidance as to how sensitive the calculations are to unknown surface tension in the HTDMA; the critical diameters have all been computed using pure water surface tension in Eq. (4), to remove those variations from the comparisons. According to Pruppacher and Klett (1997), the surface tension of inorganic salt solutions increases linearly with the concentration of the solution, so that the surface tension of the solution droplets measured in the HTDMA are actually larger than those for pure water, yielding an even larger Kelvin correction than that computed for $\sigma=0.072 \mathrm{~J} \mathrm{~m}^{-2}$. 
HTDMA data for ammonium sulfate were reprocessed, correcting with a Kelvin term computed using the composition-dependent surface tension suggested by Pruppacher and Klett (1997), parameterized as a linear function of molality. The effect of the increased surface tension acts to very modestly decrease the water activity. When the revised $a_{w}(x)$ is used to compute critical dry diameters, the difference is less than $1 \mathrm{~nm}$ even at $0.3 \%$ supersaturation, as shown in Table 2. At $1 \%$ supersaturation this difference is only $0.2 \mathrm{~nm}$. For atmospheric aerosols, it is generally expected that mixed particles contain constituents that lower, not raise, the surface tension of the solution as compared with that for pure water. Thus, the two limiting cases for processing HTDMA data that were proposed in Sect. 2.2 should provide reasonable bounds on $a_{w}(x)$.

\section{Parameterization of results}

To determine the size of a dry solute particle that would activate at a given supersaturation, the Köhler equation can be rewritten as:

$$
\ln (s)=\frac{4 \sigma_{w} M W_{w}}{\rho_{w} R T D_{p}}-\frac{v M W_{w} \rho_{s} D_{d r y}^{3}}{M W_{s} \rho_{w} D_{p}^{3}},
$$

where $D_{d r y}$ is the dry particle diameter and $D_{p}$ is the diameter of droplet at equilibrium with saturation ratio $s$. To find the critical saturation ratio, corresponding to dry diameter $D_{\text {crit }}$, the derivative of Eq. (27) is taken with respect to $D_{p}$ and set equal to zero. This gives:

$D_{c r i t}^{2}=\frac{2 v \rho_{s} \rho_{w} R T D_{d r y}^{3}}{4 \sigma_{w}}$.

Combining Eqs. (27) and (28), the dependence of the $D_{\text {crit }}$ on the supersaturation at the critical point can be derived. Recalling $S=(s-1) \times 100$, the solution gives,

$D_{\text {crit }}=\left(\frac{256 j^{3}}{27 k}\right)^{1 / 3} \times S_{\text {crit }}^{-2 / 3}=\beta \times S_{\text {crit }}^{-2 / 3}$,

$j=\left(\frac{\sigma_{w} M W_{w}}{R T \rho_{w}}\right)$

$k=\left(\frac{v \rho_{s} M W_{w}}{M W_{s} \rho_{w}}\right)$.

This yields a straightforward parameterization of critical dry diameters as predicted by simplified Köhler theory.

To extend this idea to critical dry diameters computed from Eq. (4), we parameterize Eq. (29) as simply,

$D_{\text {crit }}=\alpha \times S_{\text {crit }}^{-2 / 3}$,

where $\alpha$ is a best fit parameter for $D_{\text {crit }}$ expressed in nm and $S_{c r i t}$ in supersaturation percentage. The fits were performed for the values of $D_{\text {crit }}$ computed from HTDMA-derived water activities, and values of $\alpha$ and $\beta$ are listed in Table 1. As the only parameter that is not a constant in $\beta$ is the number of ions produced after dissociation, a best-fit $v$ can be deduced from our parameterization,

$v=\frac{256}{27}\left(\frac{\sigma_{w}}{R T}\right)^{3}\left(\frac{M W_{w}}{\rho_{w}}\right)^{2} \frac{\rho_{s}}{\alpha}$.

This effective $v$, or more accurately $v \Phi$, is listed in Table 1 for each species and each model.

\section{Summary and conclusions}

The methodology of Brechtel and Kreidenweis (2000a), describing the use of HTDMA-derived water uptake data to predict water activity as a function of solute weight percent, has been adapted to a different $G F-a_{w}$ relationship, and tested for ammonium sulfate and sodium chloride particles. Results are in reasonably good agreement with previouslypublished water activity data. Using HTDMA-derived water activities, CCN properties for the two inorganic salts are computed. Predicted critical dry diameters are in good agreement with reported experimental results, as well as with predictions of critical dry diameters using published water activity data.

The approach outlined here does not require knowledge of the solute properties, such as molecular weight and degree of dissociation, that are needed for the application of standard Köhler theory. The choice of dry density used in the calculations plays no role in the prediction of the critical supersaturation. In other words, the methodology presented here is a means for directly extrapolating the ratio of wet to dry particle volume from the subsaturated $R H$ range, in which the HTDMA operates, into the region of water supersaturation. However, knowledge of the dry density is required to accurately express solution water activity as a function of solute weight percent. We show that the method is also sensitive to the assumed dry particle shape factor, since errors in the initial dry particle volume will bias the extrapolation. Nevertheless, even for sodium chloride, the inaccuracies introduced by assuming spherical particles lead to predicted critical dry diameters within, or close to, the range associated with the direct determination of critical dry diameters using CCN counters. In Part II, we explore the effect of this uncertainty range in water activity, and thus in critical dry diameter, on the predicted droplet number concentrations in an adiabatic updraft.

One clear disadvantage of this method is that some slightly-soluble species, e.g., adipic acid, do not take up water appreciably below 95\% relative humidity, the upper limit in HTDMA experiments (Prenni et al., 2001), and thus their water and CCN activities cannot be modeled using this approach. Similarly, for mixed particles, if one component is only slightly soluble and does not go into solution for 
$R H<95 \%$, its contributions to water activity will not be captured in the HTDMA data. In Part II (Koehler et al., to be submitted, $2005^{1}$ ), we test this methodology for particles composed of selected organic species, whose water uptake and $\mathrm{CCN}$ activities have been previously reported. Further testing of the methodology for pure and mixed particles, including real atmospheric aerosols with unknown compositions, is clearly needed.

Acknowledgements. This work was supported in part by the NOAA Office of Global Programs and by the National Science Foundation under grant NSF-ATM-0071321. K. Koehler gratefully acknowledges support from a NASA Global Change Fellowship. We thank S. Clegg for useful discussions.

Edited by: U. Lohmann

\section{References}

Brechtel, F. J. and Kreidenweis, S. M.: Predicting particle critical supersaturation from hygroscopic growth measurements in the humidified TDMA, part I: Theory and sensitivity studies, J. Atmos. Sci., 57(12), 1854-1871, 2000a.

Brechtel, F. J. and Kreidenweis, S. M.: Predicting particle critical supersaturation from hygroscopic growth measurements in the humidified TDMA, Part II: Laboratory and ambient studies, J. Atmos. Sci., 57(12), 1872-1887, 2000 b.

Brooks, S. D., DeMott, P. J., and Kreidenweis, S. M.: Water uptake by particles containing humic materials and mixtures of humic materials with ammonium sulfate, Atmos. Environ., 38(13), 1859-1868, 2004.

Carrico, C. M., Kreidenweis, S. M., Malm, W. C., Day, D., Lee, T., Carrillo, J., McMeeking, G. R., and Collett Jr., J.: Hygroscopic growth behavior of a carbon dominated aerosol in Yosemite National Park, Atmos. Environ., 39 (8), 1393-1404, 2005.

Clegg, S. L., Brimblecombe, P., and Wexler, A. S.: A thermodynamic model of the system $\mathrm{H}-\mathrm{NH}_{4}-\mathrm{SO}_{4}-\mathrm{NO}_{3}-\mathrm{H}_{2} \mathrm{O}$ at tropospheric temperatures, J. Phys. Chem., 102A, 2137-2154, 1998a.

Clegg, S. L., Brimblecombe, P., and Wexler, A. S.: A thermodynamic model of the system $\mathrm{H}-\mathrm{NH}_{4}-\mathrm{Na}-\mathrm{SO}_{4}-\mathrm{NO}_{3}-\mathrm{Cl}-\mathrm{H}_{2} \mathrm{O}$ at 298.15 K, J. Phys. Chem., 102A, 2155-2171, 1998 b.

Corrigan, C. E. and Novakov, T.: Cloud condensation nucleus activity of organic compounds: a laboratory study, Atmos. Environ., 33(17), 2661-2668, 1999.

Dick, W. D., Saxena, P., and McMurry, P. H.: Estimation of water uptake by organic compounds in submicron aerosols measured during the Southeastern Aerosol and Visibility Study, J. Geophys. Res.-A, 105(D1), 1471-1479, 2000.

Facchini, M. C., Decesari, S., Mircea, M., Fuzzi, S., and Loglio, G.: Surface tension of atmospheric wet aerosol and cloud/fog droplets in relation to their organic carbon content and chemical composition, Atmos. Environ., 34(28), 4853-4857, 2000.

Gerber, H. E., Hoppel, W. A., and Wojciechowski, T. A.: Experimental-Verification of Theoretical Relationship between Size and Critical Supersaturation of Salt Nuclei, J. Atmos. Sci., 34(11), 1836-1841, 1977.

Giebl, H., Berner, A., Reischl, G., Puxbaum, H., Kasper-Giebl, A., and Hitzenberger, R.: CCN activation of oxalic and malonic acid test aerosols with the University of Vienna cloud condensation nucleus counter, J. Aerosol Sci., 33, 1623-1634, 2002.

Gysel, M., Weingartner, E., and Baltensperger, U.: Hygroscopicity of aerosol particles at low temperatures. 2. Theoretical and experimental hygroscopic properties of laboratory generated aerosols, Environ. Sci. Technol., 36, 63-68, 2002.

Köhler, H.: The nucleus in and the growth of hygroscopic droplets, Trans. Faraday Soc., 32, 1152-1161, 1936.

Kumar, P. P., Broekhuizen, K., and Abbatt, J. P. D.: Organic acids as cloud condensation nuclei: Laboratory studies of highly soluble and insoluble species, Atmos. Chem. Phys., 3, 509-520, 2003,

SRef-ID: 1680-7324/acp/2003-3-509.

Lange, N. A.: Handbook of chemistry, McGraw Hill, New York, 1969, 1961.

Low, R. D.: A theoretical study of nineteen condensation nuclei, J. de Rech. Atmos., 4, 65-78, 1969.

McDonald, J. E.: Erroneous Cloud-Physics Applications of Raoult Law, J. Meteorol., 10(1), 68-70, 1953.

Mikhailov, E., Vlasenko, S., Niessner, R., and Pöschl, U.: Interaction of aerosol particles composed of protein and salts with water vapor: hygroscopic growth and microstructural rearrangement, Atmos. Chem. Phys., 4, 323-350, 2004, SRef-ID: 1680-7324/acp/2004-4-323.

Peng, C., Chan, M. N., and Chan, C. K.: The hygroscopic properties of dicarboxylic and multifunctional acids: Measurements and UNIFAC predictions, Environ. Sci. Technol., 35(22), 44954501, 2001.

Pitzer, K. S.: Ion interaction approach: Theory and data correlation, in: Activity coefficients in electrolyte solutions, edited by: Pitzer, K. S., Boca Raton, CRC Press, 1991.

Prenni, A. J., Demott, P. J., Kreidenweis, S. M., Sherman, E. E., et al.: The effects of low molecular weight dicarboxylic acids on cloud formation, J. Phys. Chem. A, 105(50), 11 240-11248, 2001.

Pruppacher, H. R. and Klett, J. D.: Microphysics of Clouds and Precipitation, Kluwer Academic Publishers, Dordrecht, 954, 1997.

Rader, D. J. and McMurry, P. H.: Application of the Tandem Differential Mobility Analyzer to Studies of Droplet Growth or Evaporation, J. Aerosol Sci., 17(5), 771-787, 1986.

Raymond, T. M. and Pandis, S. N.: Cloud activation of singlecomponent organic aerosol particles, J. Geophys. Res.-A, 107(D24), 4787-4794, 2002.

Raymond, T. M. and Pandis, S. N.: Formation of cloud droplets by multicomponent organic particles, J. Geophys. Res.-A, 108(D15), 4469-4476, 2003.

Rissler, J., Swietlicki, E., Zhou, J., Roberts, G., Andreae, M. O., Gatti, L. V., and Artaxo, P.: Physical properties of the submicrometer aerosol over the Amazon rain forest during the wetto-dry season transition - comparison of modeled and measured CCN concentrations, Atmos. Chem. Phys., 4, 2119-2143, 2004, SRef-ID: 1680-7324/acp/2004-4-2119.

Seinfeld, J. H. and Pandis, S. N.: Atmospheric Chemistry and Physics: From air pollution to climate change, John Wiley \& Sons, Inc., New York, 1326, 1998.

Shulman, M. L., Jacobson, M. C., Carlson, R. J., Synovec, R. E., and Young, T. E.: Dissolution behavior and surface tension effects of organic compounds in nucleating cloud droplets, Geophys. Res. Lett., 23(3), 277-280, 1996. 
Tang, I. N. and Munkelwitz, H. R.: Water activities, densities, and refractive indices of aqueous sulfates and sodium nitrate droplets of atmospheric importance, J. Geophys. Res.-A, 99(D9), 18 80118 808, 1994.

Tang, I. N., Tridico, A. C., and Fung, K. H.: Thermodynamic and optical properties of sea salt aerosols, J. Geophys. Res.-A, 102(D19), 23 269-23 275, 1997.
Wise, M. E., Surratt, J. D., Curtis, D. B., Shilling, J. E., and Tolbert, M. A.: Hygroscopic growth of ammonium sulfate/dicarboxylic acids, J. Geophys. Res.-A, 108(D20), 4638-4645, 2003. 